Article

\title{
Design of New Antibacterial Enhancers Based on AcrB's Structure and the Evaluation of Their Antibacterial Enhancement Activity
}

\author{
Yi Song ${ }^{1,+}{ }^{+}$, Rongxin Qin ${ }^{1,+}$, Xichun Pan ${ }^{1}$, Qin Ouyang ${ }^{2}$, Tianyu Liu ${ }^{2}$, Zhaoxia Zhai ${ }^{1}$, \\ Yingchun Chen ${ }^{2}$, Bin $\mathrm{Li}^{1}$ and Hong Zhou ${ }^{1, *}$ \\ 1 Department of Pharmacology, College of Pharmacy, The Third Military Medical University, \\ Chongqing 400038, China; songyi19890126@163.com (Y.S.); michel_0415@163.com (R.Q.); \\ xichunpan@163.com (X.P.); zzzhaoxia@sina.com (Z.Z.); libin6033@sina.com (B.L.) \\ 2 Department of Medicinal Chemistry, College of Pharmacy, The Third Military Medical University, \\ Chongqing 400038, China; ouyangq@tmmu.edu.cn (Q.O.); liutianyu@tmmu.edu.cn (T.L.); \\ ycchen@scu.edu.cn (Y.C.) \\ * Correspondence: zhouh64@163.com; Tel./Fax: +86-23-6875-2366 \\ + These authors contributed equally to this work.
}

Academic Editor: David Arráez-Román

Received: 22 June 2016; Accepted: 10 November 2016; Published: 18 November 2016

\begin{abstract}
Previously, artesunate (AS) and dihydroartemisinine 7 (DHA7) were found to have antibacterial enhancement activity against Escherichia coli via inhibition of the efflux pump AcrB. However, they were only effective against E. coli standard strains. This study aimed to develop effective antibacterial enhancers based on the previous work. Our results demonstrate that 86 new antibacterial enhancers were designed via 3D-SAR and molecular docking. Among them, DHA27 had the best antibacterial enhancement activity. It could potentiate the antibacterial effects of ampicillin against not only E. coli standard strain but also clinical strains, and of $\beta$-lactam antibiotics, not non- $\beta$-lactamantibiotics. DHA27 could increase the accumulation of daunomycin and nile red within E. coli ATCC 35218, but did not increase the bacterial membrane permeability. DHA27 reduced $a c r B$ 's mRNA expression of E. coli ATCC 35218 in a dose-dependent manner, and its antibacterial enhancement activity is related to the degree of $a c r B$ mRNA expression in $E$. coli clinical strains. The polypeptides from AcrB were obtained via molecular docking assay; the pre-incubated polypeptides could inhibit the activity of DHA27. Importantly, DHA27 had no cytotoxicity on cell proliferation. In conclusion, among newly designed antibacterial enhancers, DHA27 had favorable physical and pharmacological properties with no significant cytotoxicity at effective concentrations, and might serve as a potential efflux pump inhibitor in the future.
\end{abstract}

Keywords: antibacterial enhancer; AcrB inhibitor; DHA27; molecular mechanism

\section{Introduction}

Multidrug resistance (MDR) in gram-negative pathogens, including Escherichia coli (E. coli), Pseudomonas aeruginosa, and Klebsiellap neumoniae, has become a major concern in public health [1]. The resistant mechanism of MDR gram-negative strains is closely related to efflux pumps of the resistance nodulation division (RND) family [2]. The major RND efflux system in E. coli is AcrAB-TolC, which consists of a cell membrane transporter (AcrB), an inner membrane channel (TolC) and an adaptor protein (AcrA) [3]. Substrates of AcrAB-TolC get into the periplasmic space through porin or by diffusion through the lipid bilayer, where they are captured by AcrB. The AcrB transporter extrudes the compounds into the TolC channel and to the exterior using the proton motive force [4]. Therefore, the inhibition of AcrB function can inhibit the functions of AcrAB-TolC efflux pump. 
Recently, efflux pump inhibitors (EPIs) / AcrB inhibitors have emerged as a hot topic and have attracted the interest of many researchers.

Biochemical studies have verified that EPIs can be used as synergism therapies with antibiotics to improve the antibacterial potency at low antibiotic concentrations to reduce the emergence of resistance [5-7]. So far, several potent AcrB inhibitors including phenylalanylarginine- $\beta$-Naphthylamide (PA $\beta N$ ), 1-(1-naphthylmethyl)-piperazine (NMP), D13-9001, and pyranopyridines (MBX2319) have been described in the literature [8]. However, none of them is being used clinically.

Previously, it was found that artesunate (AS), an antimalarial agent, had no direct antibacterial activity itself, but it could significantly enhance the antibacterial effects of $\beta$-lactam antibiotics against E. coli ATCC 35218 in vitro, which might be associated with the efflux pump AcrB [9]. Based on the results of molecular docking experiments, a new antibiotic enhancer named as dihydroartemisinine 7 (DHA7) was developed by removing the carbonyl group and replacing the carboxyl group with imidazole in the succinate tail of AS. DHA7 has better antibacterial enhancement activity of $\beta$-lactam antibiotics than AS does [10]. This experiment proved that the strategy of changing the chemical structure of the succinate tail of AS to obtain a better active compound targeting AcrB was feasible. However, AS and DHA7 were effective only against standard strains. Most of E. coli clinical strains were not susceptible to them. Additionally, the aqueous solubility of these compounds was so poor that they could not be developed for clinical application. This study reported the whole process from design, synthesis, to evaluation of a new antibacterial enhancer DHA27 with better activity than those of AS and DHA7, and its possible molecular mechanism.

\section{Results}

\subsection{Eighty-Six New Compounds Are Designed Based on Structure-Activity Relationship Analysis of} 18 Artemisinin Derivatives from a Previous Work

Eighteen artemisinin (ART) derivatives have been derived from a previous work so far [10]. DHA7 was selected as the molecular template (Figure 1A). This compound was chosen as it was the most potent enhancer among 18 compounds. Within the best fit conformation for alignment, the left part of the figure shows the nucleus structure of ART and the right part shows the side chains of derivatives (Figure 1B).

The statistical parameters of CoMFA met the requirement and are summarized in Table S1. The results showed that (1) if steric hindrance increased in yellow part, bioactivity would decrease (yellow part); (2) if there were big steric hindrance groups on C-3 in side chains (green part), antibacterial enhancement activity would increase; (3) if there were electron-withdrawing groups at C-5 and C-7 (red part) and the electron-donating groups at O-1 (blue part), antibacterial enhancement activity would increase (Figure 1C). Therefore, 86 new compounds were designed by computer according to the aforementioned findings.

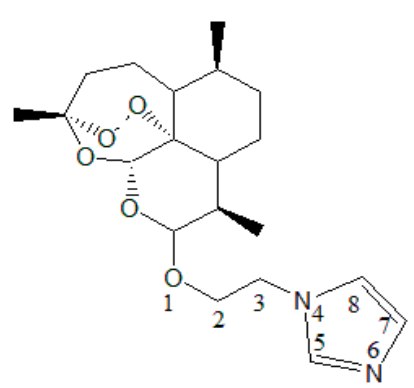

DHA 7

(A)

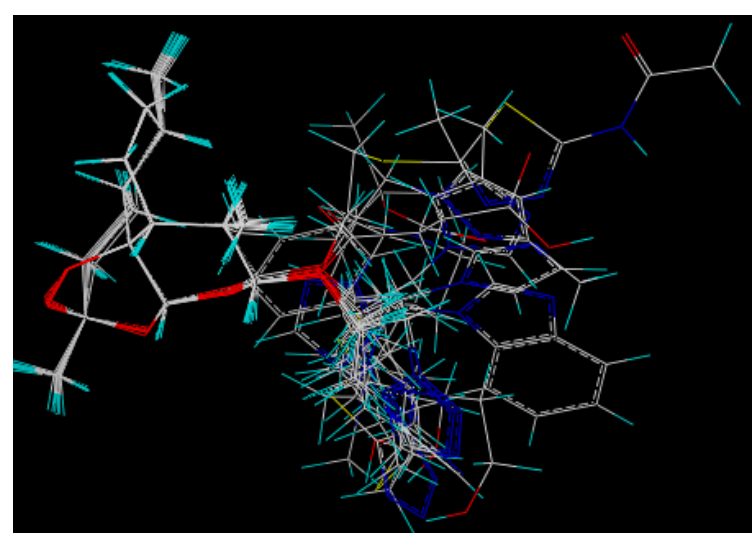

(B)

Figure 1. Cont. 


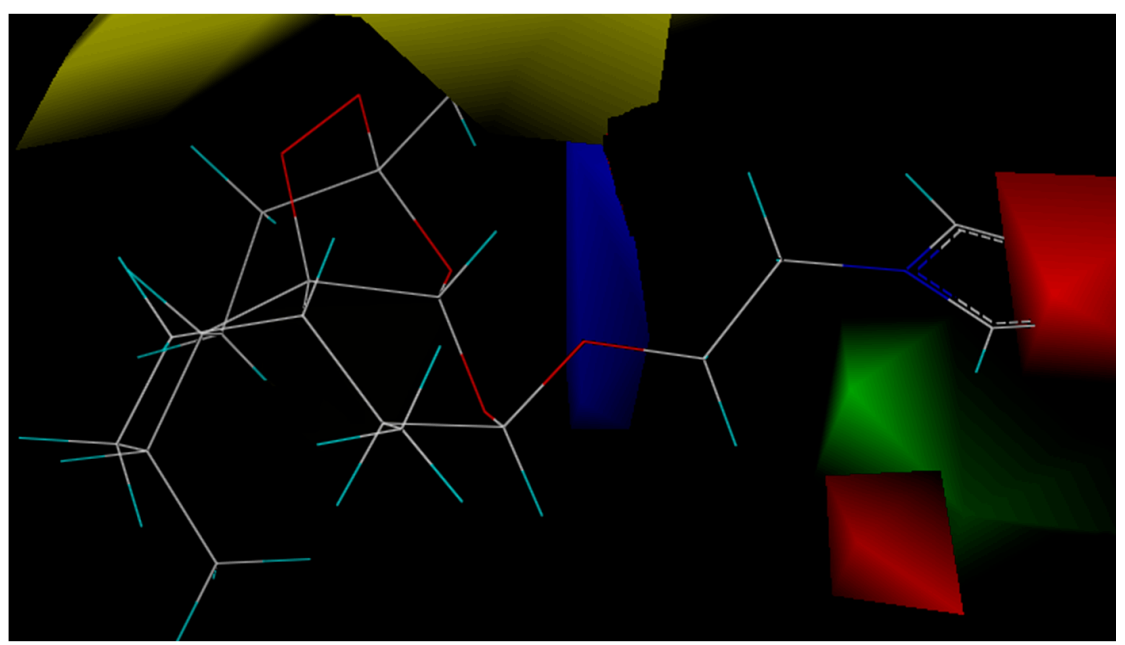

(C)

Figure 1. Three-dimensional structure-activity relationship (3D-SAR) analysis. (A) DHA7 as a molecular template; (B) A total of 18 compounds were used for database alignment. The molecular energy minimization of each compound was calculated in the compute mode; (C) Comparative molecular field analysis results (including steric and electrostatic fields).

\subsection{Twenty-Two Compounds Combined with the Active Binding Pocket from AcrB Are Selected Based on Molecular Docking}

Previous works verified that AS and DHA7 had antibacterial enhancement activity while ART and DHA did not have such activity $[9,10]$. Therefore, molecular docking was first performed on ART and three ART derivatives including DHA, AS, and DHA7 to identify a possible binding pocket for their potency. Following this, 86 compounds designed by computer were bound to this pocket to screen the compounds that could bind to this pocket well and might be supposed to have antibacterial enhancement activity. The results showed that AS and DHA7 (with bioactivity) bound at different positions with ART and DHA (without bioactivity) and that the binding position of AS and DHA7 might be important for their bioactivity (Figure 2A).

The binding pocket of AS and DHA7 was lined by hydrophobic (Phe136, Phe178, and Phe615) and polar (Gln176, Ser46, and Tyr327) residues, which were partially overlapped with those of substrates such as minocycline and doxorubicin [11] and inhibitors such as MBX2319 [12] bound to AcrB. AS and DHA7 interacted with a similar site of amino acid residue that was located at the distal binding pocket. The oxygen atom of the peroxide bridge of the nucleus structure and the oxygen atom of the carboxyl group of the side chain of AS interacted with Gln176 and Tyr327 via hydrogen bonding at a distance of 2.1 and $2.0 \AA$, respectively; and the oxygen atom of carbonyl of the side chain interacted with Phe178 via the electron cloud-stacking effect. The distance between oxygen atom and six carbon atoms on phenyl of Phe178 was $4.4 \pm 0.7 \AA$ (Figure 2B,C). The oxygen atom of the six-membered ring of the nucleus structure and nitrogen atom of imidazole of DHA7 interacted with Gln176 and Phe136 via hydrogen bonding at a distance of 2.2 and $3.1 \AA$, respectively. The oxygen atom of the side chain interacted with Phe178 via the electron cloud-stacking effect. The distance between oxygen atom and six carbon atoms on phenyl of Phe178 was $4.1 \pm 0.9 \AA$ (Figure 2D,E). The results demonstrated that Phe136, Gln176, Phe178, and Tyr327 might be the important binding sites in the distal pocket (DP) of AcrB for AS and its analogues which might have antibacterial enhancement activity.

Based on the aforementioned analysis, 86 compounds were docked in the position to which AS and DHA7 bound to get better binding compounds with better antibacterial enhancement activity. The results showed that only 22 compounds bound well to that position (Table S2). 


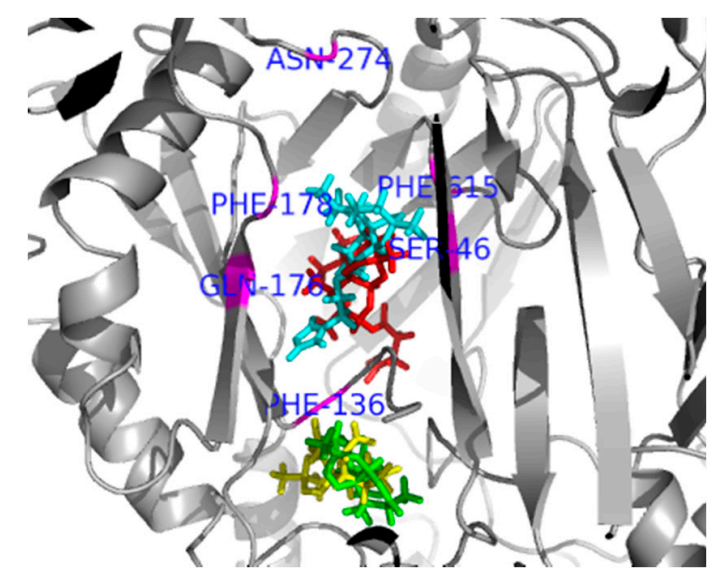

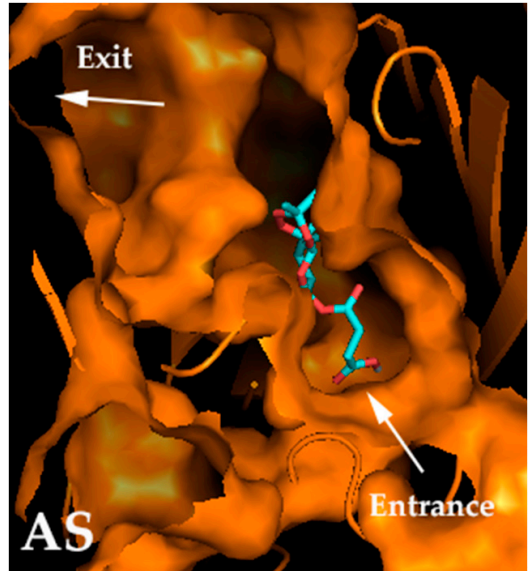

(B)

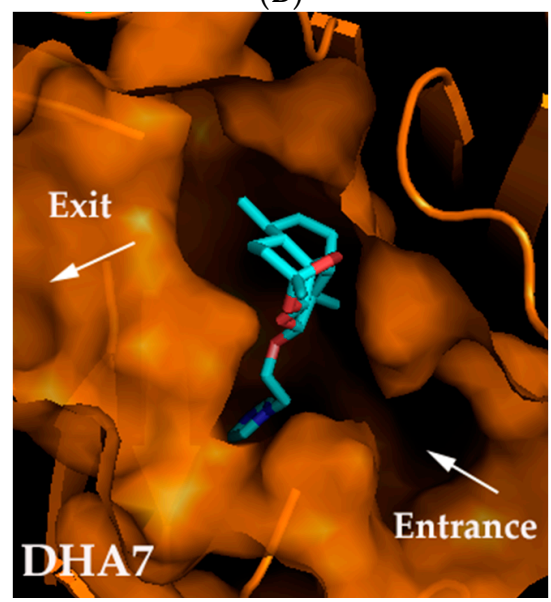

(D)

(A)

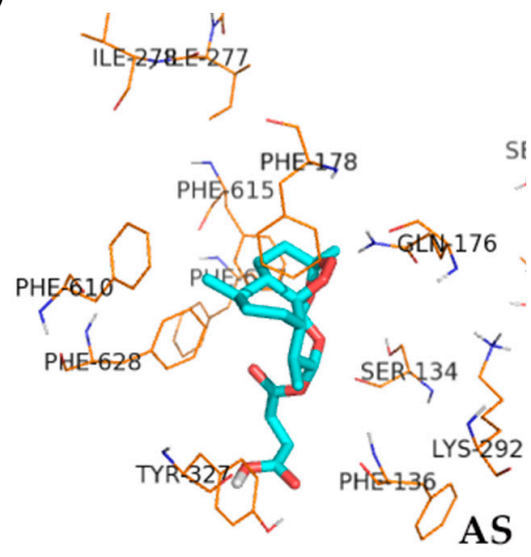

(C)

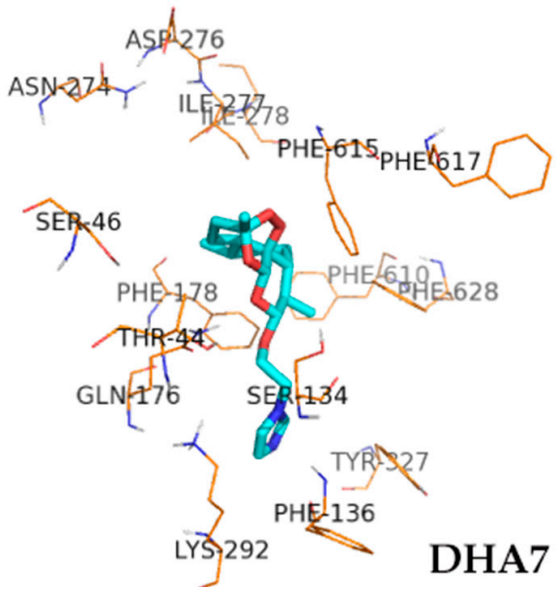

(E)

Figure 2. Molecule docking of ART, DHA, AS, and DHA7 to AcrB. Surflex-Dock that adopted an empirical scoring function was employed for molecular docking. The crystal structure of AcrB (PDB ID, 2DRD) was obtained from Protein Data Bank. The molecular docking results were analyzed and represented in the PyMOL 1.3 visualization software. Proteins are shown in gray and orange. The compounds are shown as thick sticks colored according to the compound structure (Figure 2A: red, AS; cyan, DHA7; green, ART; yellow, DHA) and the atom type (Figure 2B-E: red, oxygen; cyan, carbon; dark blue, nitrogen), and residues are shown in brown and marked. (A) ART and three ART derivatives including DHA, AS, and DHA7 bind to AcrB; (B) Longitudinal section of substrate translocation pathway when AS was docked with AcrB; (C) Cartoon view of AS docked with AcrB; (D) Longitudinal section of substrate translocation pathway when DHA7 was docked with AcrB; (E) Cartoon view of DHA7 docked with AcrB. 
2.3. DHA27 from Four Representative Compounds Has the Best Antibacterial Enhancement Activity

Based on the results of 3D-SAR and molecular docking, four compounds, named as DHA25-DHA28, with a higher total score (Table S3) and simple synthetic routes from 22 compounds were selected and synthesized (Figure 3).

The activities of these compounds were investigated using standard strain E. coli ATCC 35218. Because E. coli ATCC 35218 is a $\beta$-lactamase-producing strain, a $\beta$-lactamase inhibitor TZB was added during the MIC test to exclude the disturbing effects of $\beta$-lactamase. The results showed that MICs of DHA25-DHA28 alone were higher than $512 \mathrm{mg} / \mathrm{L}$ (Table 1A), which meant they had no direct antibacterial activities. When DHA27, DHA7, and AS were combined with AMP, FICI values were $0.31,0.38$, and 0.5 , respectively (Table $1 \mathrm{~B}$ ), indicating they all had antibacterial enhancement activity. Among three compounds, DHA27 had the smallest FICI, demonstrating that DHA27 had the best antibacterial enhancement activity.
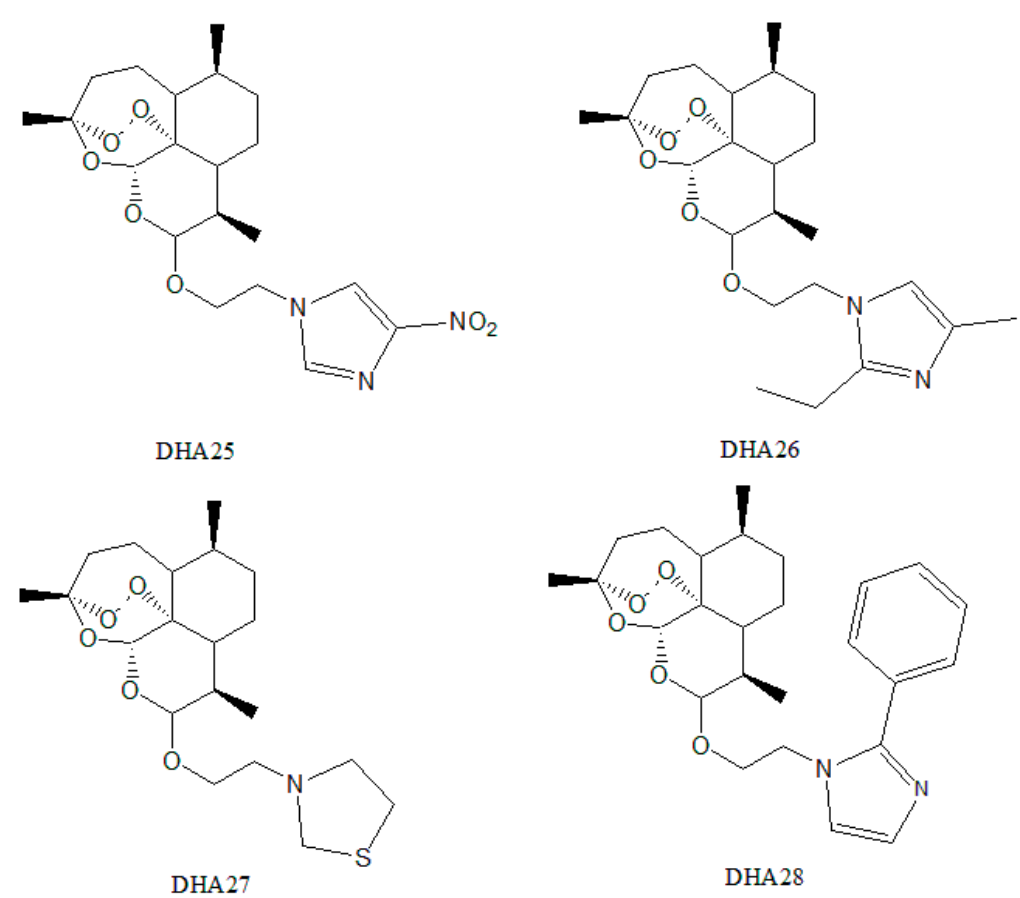

Figure 3. Structure of four representative compounds chosen to be synthesized and named as DHA25-DHA28.

Table 1. Effect of AS, DHA7, and DHA25-DHA28 alone and in combination with AMP against E. coli ATCC 35218.

A

\begin{tabular}{cc}
\hline Agents & MIC (mg/L) \\
\hline AS & $>4096$ \\
DHA7 & 1024 \\
DHA-25 & $>512$ \\
DHA-26 & $>512$ \\
DHA-27 & 1024 \\
DHA-28 & $>512$ \\
AMP + TZB & 16 \\
\hline
\end{tabular}


Table 1. Cont.

\section{B}

\begin{tabular}{cc}
\hline Drug Concentrations & FICI \\
\hline 1/8 MIC AS + 1/4MIC AMP & 0.50 \\
1/4 MIC DHA7 + 1/4 MIC AMP & 0.38 \\
1/2 MIC DHA25 + 1/2 MIC AMP & 1.00 \\
1/2MIC DHA26 + 1/4 MIC AMP & 0.75 \\
1/16MIC DHA27 + 1/4 MIC AMP & 0.31 \\
1 MIC DHA28 + 1/8 MIC AMP & 1.13 \\
\hline
\end{tabular}

(A) MICs (mg/L) of AS, DHA7, DHA25-DHA28, and AMP alone against E. coli ATCC 35218. For this, 96-well plates were incubated for $24 \mathrm{~h}$ at $37{ }^{\circ} \mathrm{C}$ in an incubator. The MIC values were taken at the lowest drug concentration at which observable growth was inhibited; (B) MICs (mg/L) of AS, DHA7, and DHA25-DHA28 in combination with AMP against E. coli ATCC 35218. Synergy testing was performed by the checkerboard method. The calculation of FICIs is described in the Materials and method section.

\subsection{DHA27 Potentiates Antibacterial Effects of AMP against Not Only E. coli Standard Strain But Also Clinical Strains}

DHA27 had the best antibacterial enhancement activity among four compounds, but its aqueous solubility was very poor (maximum solubility was $512 \mathrm{mg} / \mathrm{L}$ in $5 \%$ DMSO and $128 \mathrm{mg} / \mathrm{L}$ in water at room temperature). To carry out subsequent experiments, its aqueous solubility should be improved. The results showed that if DHA27 was converted into corresponding hydrochloride salt, its aqueous solubility markedly improved; the solubility of DHA27 hydrochloride was better than that of DHA27 $(<2048 \mathrm{mg} / \mathrm{L}$ in water at room temperature).

For the bacterial dynamic growth curve assay, AS and DHA7 were used as controls. DHA27 hydrochloride (DHA27 for short, $64 \mathrm{mg} / \mathrm{L}$ ) only slightly delayed the growth of ATCC 35218 (Figure 4A). However, DHA27 in combination with AMP could significantly inhibit the bacterial growth from 4 to $24 \mathrm{~h}$ (Figure 4B). This result was also supported by the colony counting method (Figure S3).

Then, 40 E. coli clinical strains were used to evaluate the activity of DHA27. The results showed that these clinical strains were highly resistant to AMP and $\mathrm{MIC}_{50}$ was $128 \mathrm{mg} / \mathrm{L}$. When 256, 128, and $64 \mathrm{mg} / \mathrm{L}$ of DHA27 was used in combination with AMP, the average FICI was 0.36, 0.31 and 0.27, respectively; the effective rate was $47 \%, 78 \%$, and $66 \%$, respectively (Table 2). The aforementioned results indicated that DHA27 had the antibacterial enhancement activity of AMP against not only E. coli standard strain ATCC 35218 but also most clinical strains.

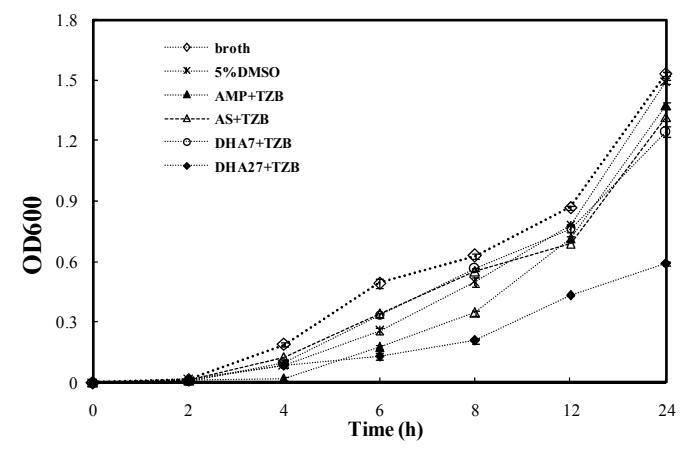

(A)

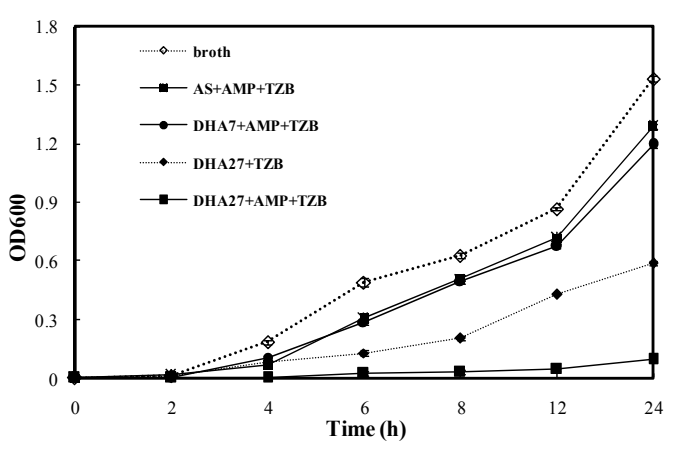

(B)

Figure 4. Dynamic growth curves of E. coli ATCC 35218. E. coli ATCC 35218 from the exponential phase was diluted with LB broth to $1.0 \times 10^{6} \mathrm{cfu} / \mathrm{mL}$. Then, $64 \mathrm{mg} / \mathrm{L}$ artesunate (AS), DHA7 and DHA27 alone, and in combination with ampicillin (AMP)/tazobactam (TZB) were added to bacterial suspensions. Broth and 5\% DMSO were negative control and solvent control, respectively. The bacterial growth was determined by measuring $\mathrm{OD}_{600}$ at regular intervals. (A) The effect of drugs alone on growth of E. coli ATCC 35218; (B) The effect of drugs in combination of AMP on growth of E. coli ATCC 35218. 
Table 2. Effect of DHA27 on antibacterial activity of AMP against 40 clinical E. coli strains.

\begin{tabular}{|c|c|c|c|c|c|c|c|c|}
\hline \multirow{3}{*}{ Antibiotic } & \multirow{3}{*}{$n$} & \multirow{3}{*}{$\mathrm{MIC}_{50}$} & \multicolumn{6}{|c|}{ Concentration of DHA27 (mg/L) } \\
\hline & & & \multicolumn{2}{|r|}{256} & \multicolumn{2}{|r|}{128} & \multicolumn{2}{|r|}{64} \\
\hline & & & FICI & Effective Rate & FICI & Effective Rate & FICI & Effective Rate \\
\hline $\mathrm{AMP}+\mathrm{TZB}$ & 40 & 128 & 0.36 & $47 \%$ & 0.31 & $78 \%$ & 0.27 & $65 \%$ \\
\hline
\end{tabular}

Synergy testing was performed for 40 clinical E. coli strains by the checkerboard method. Studies of synergistic activities of different concentrations of DHA27 and ampicillin (AMP)/tazobactam (TZB) were performed. The calculation of FICI and the explanation are described in the Materials and methods section. FICI, Fractional inhibitory concentration index. Effective rate $=$ the number of strains which DHA27 or PA $\beta N$ has antibacterial enhancement activity/Total number of tested strains.

\subsection{DHA27 Only Potentiates Antibacterial Effects of $\beta$-Lactam Antibiotics Not Non- $\beta$-Lactam Antibiotics} against Clinical E. coli Strains

Previous studies found that AS had a better antibacterial enhancement effect when combined with $\beta$-lactam antibiotics than with other kinds of antibiotics. Herein, the antibacterial enhancement activity of DHA27 combined with $\beta$-lactam antibiotics and non- $\beta$-lactam antibiotics, was also detected. $\mathrm{PA} \beta \mathrm{N}$, as a known AcrB inhibitor, was used as a control the agent.

The results showed that the average FICIs of six strains were almost lower than 0.5 when DHA27 was combined with $\beta$-lactam antibiotics including AMP, CPA, OXA, and PIP in a concentration-dependent manner, while FICIs were higher than 0.5 when DHA27 was combined with non- $\beta$-lactam antibiotics such as GAT and AZI. Interestingly, PA $\beta N$ did not work when it was combined with $\beta$-lactam antibiotics at every concentration. It only worked when it was combined with GAT and AZI at the highest concentration $(128 \mathrm{mg} / \mathrm{L})$; the FICIs were 0.38 and 0.32 , respectively (Table 3).

The aforementioned results suggested that DHA27 potentiated the antibacterial effects of $\beta$-lactam antibiotics, not non- $\beta$-lactam antibiotics, against clinical E. coli strains, and DHA27 had better antibacterial enhancement activity when combined with $\beta$-lactam antibiotics compared with PA $\beta N$. 
Table 3. Effect of DHA27 and PAßN on antibacterial effects of six antibiotics on six E. coli strains.

\begin{tabular}{|c|c|c|c|c|c|c|c|c|c|c|c|c|c|c|c|}
\hline \multirow{4}{*}{ Strains } & \multirow{4}{*}{$\mathbf{n}$} & \multirow{4}{*}{ Antibiotics } & \multirow{4}{*}{$\mathrm{MIC}_{50}$} & \multicolumn{12}{|c|}{ Concentration of DHA27/PA $\beta N$ (mg/L) } \\
\hline & & & & \multicolumn{4}{|c|}{32} & \multicolumn{4}{|c|}{64} & \multicolumn{4}{|c|}{128} \\
\hline & & & & \multicolumn{2}{|c|}{ DHA27 } & \multicolumn{2}{|c|}{$P A \beta N$} & \multicolumn{2}{|c|}{ DHA27 } & \multicolumn{2}{|c|}{$P A \beta N$} & \multicolumn{2}{|c|}{ DHA27 } & \multicolumn{2}{|c|}{$\mathbf{P A} \beta \mathbf{N}$} \\
\hline & & & & FICI & $\begin{array}{c}\text { Effective } \\
\text { Rate }\end{array}$ & FICI & $\begin{array}{c}\text { Effective } \\
\text { Rate }\end{array}$ & FICI & $\begin{array}{c}\text { Effective } \\
\text { Rate }\end{array}$ & FICI & $\begin{array}{c}\text { Effective } \\
\text { Rate }\end{array}$ & FICI & $\begin{array}{c}\text { Effective } \\
\text { Rate }\end{array}$ & FICI & $\begin{array}{c}\text { Effective } \\
\text { Rate }\end{array}$ \\
\hline \multirow{6}{*}{$\begin{array}{c}\text { E. coli } \\
\text { Clinical } \\
\text { strains }\end{array}$} & \multirow{6}{*}{6} & $\mathrm{AMP}+\mathrm{TZB}$ & 32 & 0.48 & $34 \%$ & 0.67 & $0 \%$ & 0.21 & $100 \%$ & 0.64 & $0 \%$ & 0.24 & $100 \%$ & 0.61 & $33 \%$ \\
\hline & & $\mathrm{CPA}+\mathrm{TZB}$ & 256 & 0.45 & $50 \%$ & 0.69 & $0 \%$ & 0.33 & $83 \%$ & 0.72 & $0 \%$ & 0.23 & $100 \%$ & 0.56 & $0 \%$ \\
\hline & & $\mathrm{OXA}+\mathrm{TZB}$ & 256 & 0.42 & $50 \%$ & 0.78 & $0 \%$ & 0.32 & $83 \%$ & 0.74 & $0 \%$ & 0.29 & $83 \%$ & 0.51 & $33 \%$ \\
\hline & & PIP + TZB & 8 & 0.53 & $50 \%$ & 0.82 & $0 \%$ & 0.24 & $100 \%$ & 0.69 & $0 \%$ & 0.26 & $100 \%$ & 0.84 & $0 \%$ \\
\hline & & GAT & 2 & 0.76 & $0 \%$ & 0.65 & $17 \%$ & 0.59 & $0 \%$ & 0.51 & $33 \%$ & 0.58 & $17 \%$ & 0.38 & $83 \%$ \\
\hline & & AZI & 32 & 0.83 & $0 \%$ & 0.93 & $0 \%$ & 0.68 & $17 \%$ & 0.42 & $50 \%$ & 0.52 & $50 \%$ & 0.32 & $83 \%$ \\
\hline
\end{tabular}

Synergy testing was performed for six E. coli strains by the checkerboard method. Studies of synergistic activities of different concentrations of dihydroartemisinine 27 (DHA27), phe-Arg $\beta$-naphthylamide (PA $\beta N)$, and several kinds of antibiotics, including ampicillin (AMP), cefpiramide (CPA), oxacillin (OXA), piperacillin (PIP), gatifloxacin (GAT), and azithromycin (AZI), were performed. The calculation of FICI and the explanation are described in the Materials and methods section. FICI, Fractional inhibitory concentration index. Effective rate $=$ The number of strains which DHA27 and PA $\beta N$ has antibacterial enhancement activity against them/Total number of tested strains. 
2.6. DHA27 Increases the Accumulation of Daunorubicin and Nile Red within E. coli ATCC 35218 But Does Not Change the Bacterial Membrane Permeability

To investigate the molecular mechanisms of DHA27 was tightly related to AcrB just like AS, two methods were used to observe the effect ofDHA27 on daunorubicin and nile red accumulation.

Daunorubicin is not a $\beta$-lactam antibiotic, and it can emit red autofluorescence [9]; therefore, it can be traced and observed easily and hence used as a tracer agent. The results showed both AS and DHA27 could increase the daunorubicin accumulation within E. coli ATCC 35218 in dose- and time-dependent manners, but the effective concentration of DHA27 was much lower than that of AS (Figure 5A,B). Nile red is only a weakly fluorescent in aqueous solution, but undergoes a significant increase in fluorescent quantum yield when in nonpolar environment such as the cell membrane. Cells were preloaded with nile red in the absence or presence of DHA27. Once the cells were energized by the addition of glucose, the efflux of nile red could be observed as a drop in fluorescence. The result was similar to that from daunorubicin accumulation assay. DHA27 could inhibit the efflux of nile red just like AcrB inhibitor PA $\beta N$ (Figure S5).

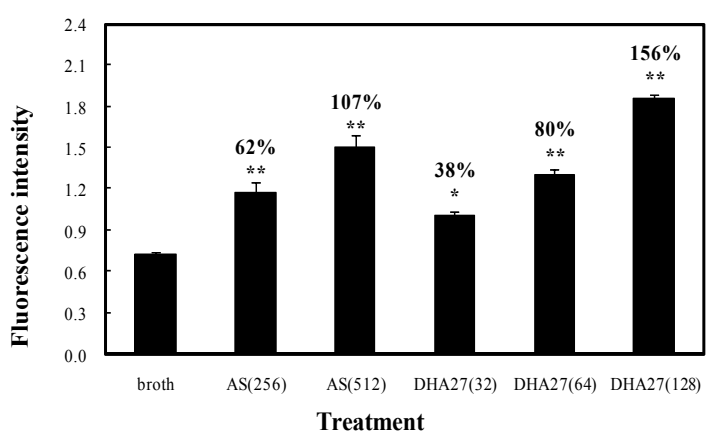

(A)

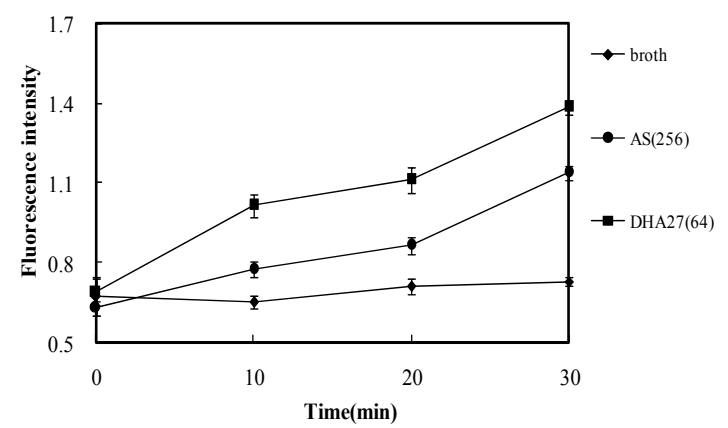

(B)

Figure 5. Effect of DHA27 on daunorubicin accumulation within E. coli ATCC 35218. Daunorubicin accumulation within E. coli ATCC 35218 pretreated with artesunate (AS) and DHA27. (A) E. coli ATCC 35218 was treated with artesunate (AS 256, $512 \mathrm{mg} / \mathrm{L}$ ) and DHA27 (32, 64, and $128 \mathrm{mg} / \mathrm{L}$ ) and cultivated at $37^{\circ} \mathrm{C}$ and $100 \mathrm{rpm}$ for $6 \mathrm{~h}$, and then harvested by centrifugation at $4000 \mathrm{rpm}$ for $5 \mathrm{~min}$. After washing three times and resuspending, the bacterial suspension was adjusted to $\mathrm{OD}_{600}$ 1.0. Bacteria were incubated with daunorubicin $(40 \mathrm{mg} / \mathrm{L})$ in the dark at $37^{\circ} \mathrm{C}$ for $30 \mathrm{~min}$. The numerical values on the column were increased percentage of treatment group than broth group; (B) E. coli ATCC 35218 was treated with artesunate (AS, $256 \mathrm{mg} / \mathrm{L})$ and DHA27 $(64 \mathrm{mg} / \mathrm{L})$ and cultivated at $37^{\circ} \mathrm{C}$ and $100 \mathrm{rpm}$ for $6 \mathrm{~h}$, and then harvested by centrifugation at $4000 \mathrm{rpm}$ for $5 \mathrm{~min}$. After washing three times and resuspending, the bacterial suspension was adjusted to $\mathrm{OD}_{600}$ 1.0. Bacteria were incubated with daunorubicin $(40 \mathrm{mg} / \mathrm{L})$ in the dark at $37^{\circ} \mathrm{C}$ for $0,10,20$, and $30 \mathrm{~min}$. Then, $0.5 \mathrm{~mL}$ of bacteria was collected. Bacteria were washed three times and resuspended in PBS. Quantitative determination of daunorubicin accumulation in the presence of AS and DHA27 was determined by fluorospectrophotometry at the emission wavelength of $467 \mathrm{~nm}$ and excitation wavelength of $588 \mathrm{~nm}$. ${ }^{*} p<0.05$ compared with broth, ${ }^{* *} p<0.01$ compared with broth. 
As well-known, decreased drug accumulation might be the result of damaged permeability of bacterial membrane. To rule out this possibility of changed permeability of bacterial membrane, the effect of DHA27 on bacterial membrane permeability was observed via examining the hydrolysis rate of a chromogenic $\beta$-lactam, nitrocefin by E. coli ATCC 35218. Hydrolysis of nitrocefin by the $\beta$-lactamase releases a colored compound that can be measured at $490 \mathrm{~nm}$. The rate of nitrocefin hydrolysis is limited by the rate of diffusion across the inner membrane, hence an increased rate of hydrolysis of nitrocefin would be the indicator of decreased membrane permeability. The result showed each concentration of DHA27 $(32,64$, and $128 \mathrm{mg} / \mathrm{L})$ did not increase nitrocefin hydrolysis but PA $\beta N$ ( $256 \mathrm{mg} / \mathrm{L}$, the effective work concentration) did, demonstrating DHA27 did not change the permeability of bacterial membrane (Figure S6).

Therefore, DHA27 had stronger antibacterial enhancement activity and its bioactivity was closely related to the inhibition of efflux pump and did not affect the bacterial membrane permeability.

\subsection{DHA27 Loses Antibacterial Enhancement Activity of AMP against E. coli AG100A and Regains it against AG100A/pET28a-AcrB}

AcrAB-TolC is one of the most important efflux pumps in E. coli. A previous work verified that the antibacterial enhancement activity of AS was associated with the inhibition of AcrB, and DHA27 was also designed targeting AcrB. To verify whether DHA27 was an AcrB inhibitor, E. coli AG100A lacking AcrA and AcrB and AG100A/pET28a-AcrB re-expressing AcrB, the recombinant AG100A harboring pET28a-AcrB, were used. PA $\beta \mathrm{N}$ was also used as a control agent.

The results showed that the MICs of AMP, CPA, OXA, PIP, GAT, AZI, PA $\beta N$, and DHA27 were high for E. coli ATCC 35218 and AG100A/pET28a-AcrB (E. coli AG100A transformed with plasmid pET28a-AcrB, Table 4), indicating that the two strains were resistant to these drugs. In contrast, the MICs of all agents except PA $\beta N$ and DHA27 for E. coli AG100A were lower, indicating that AG100A was sensitive and PA $\beta N$ and DHA27 had no antibiotic effects themselves. When DHA27 was combined with $\beta$-lactam antibiotics including AMP, CPA, OXA, and PIP, FICIs were less than 0.5 for ATCC 35218 and AG100A/pET28a-AcrB. When DHA27 was combined with non- $\beta$-lactam antibiotics including GAT and AZI, FICIs were more than 0.5 for these two strains. Interestingly, $\mathrm{PA} \beta \mathrm{N}$ was just the opposite (Table 4). FICIs were more than 0.5 when DHA27 and PA $\beta \mathrm{N}$ were combined with all antibiotics against E. coli AG100A, suggesting that DHA27 and PA $\beta N$ lost their properties of enhancement of antibacterial effect of antibiotics against strains lacking or with low $a c r B$ expression but regained their activities against strains with $a c r B$ expression; DHA27 and PA $\beta N$ were both AcrB inhibitors.

Table 4. Effect of DHA27 and PA $\beta N$ in combination with different antibiotics on antibacterial activity against three E. coli strains.

\begin{tabular}{|c|c|c|c|c|c|c|c|c|c|}
\hline \multirow{4}{*}{ Antibiotics } & \multicolumn{9}{|c|}{ E. coli ATCC 35218 E. coli AG100 E. coli AG100A/pET28a-AcrB } \\
\hline & \multirow[b]{2}{*}{ No Drug } & \multicolumn{2}{|c|}{$64 \mathrm{mg} / \mathrm{L}$} & \multicolumn{3}{|c|}{$64 \mathrm{mg} / \mathrm{L}$} & \multirow[b]{2}{*}{ No Drug } & \multicolumn{2}{|c|}{$64 \mathrm{mg} / \mathrm{L}$} \\
\hline & & DHA27 $^{\text {a }}$ & $P a \beta N^{b}$ & No Drug & DHA27 $^{\text {c }}$ & $P a \beta N d$ & & DHA27 ${ }^{\mathrm{e}}$ & $P a \beta N^{f}$ \\
\hline & MIC & FICI & FICI & MIC & FICI & FICI & MIC & FICI & FICI \\
\hline AMP & 32 & 0.31 & 0.75 & 2 & 1.06 & 1.13 & 512 & 0.31 & 0.75 \\
\hline CPA & 8 & 0.19 & 1.25 & 0.5 & 0.56 & 1.13 & 4 & 0.31 & 1.25 \\
\hline OXA & 128 & 0.13 & 1.25 & 8 & 0.56 & 1.13 & 512 & 0.09 & 0.5 \\
\hline PIP & 8 & 0.19 & 0.75 & 0.25 & 1.06 & 1.13 & 4 & 0.38 & 1.25 \\
\hline GAT & 0.0625 & 1.06 & 0.38 & 0.016 & 1.06 & 1.13 & 0.0625 & 1.06 & 0.5 \\
\hline AZI & 32 & 0.56 & 0.28 & 0.5 & 1.06 & 0.63 & 32 & 0.56 & 0.38 \\
\hline
\end{tabular}

${ }^{a}$ The MIC of DHA27 against E. coli ATCC 35218 is $1024 \mathrm{mg} / \mathrm{L} ;{ }^{\mathrm{b}}$ The MIC of $\mathrm{Pa} \beta \mathrm{N}$ against $E$. coli ATCC 35218 was $256 \mathrm{mg} / \mathrm{L}^{\mathrm{c}}{ }^{\mathrm{C}}$ The MIC of DHA27 against E. coli AG100 was $1024 \mathrm{mg} / \mathrm{L} ;{ }^{\mathrm{d}}$ The MIC of PA $\beta \mathrm{N}$ against $E$. coli AG100 was $512 \mathrm{mg} / \mathrm{L}$; ${ }^{\mathrm{e}}$ The MIC of DHA27 against E. coli AG100A/pET28a-AcrB was $1024 \mathrm{mg} / \mathrm{L}{ }^{\mathrm{f}}{ }^{\mathrm{f}}$ The MIC of PA $\beta N$ against E. coli AG100A/pET28a-AcrB was $256 \mathrm{mg} / \mathrm{L}$. Synergistic activities of DHA27 and PA $\beta N$ in combination with antibiotics on three $E$. coli strains were tested by checkerboard method. The calculation of FICIs was described in the Materials and method section. FICI, Fractional inhibitory concentration index; MIC, minimum inhibitory concentration. 
2.8. DHA27Alone Markedly Reduces acrB's mRNA Expression of E. coli ATCC 35218 in a Dose-Dependent Mannerand Its Antibacterial Enhancement Activity Is Related to the Degree of acrB mRNA Expression in E. coli Clinical Strains

Previous results showed DHA27 increased daunorubicin and nile red accumulation and lost its antibacterial enhancement activity of AMP in $a c r B$ knock out strain, and regained antibacterial enhancement activity in $a c r B$ acquired strain, suggesting the activity of DHA27 was tightly related to AcrB. Therefore, in the present experiment, the effect of DHA27 on the mRNA expression of $a c r B$ in E. coli ATCC 35218 was investigated. The results showed DHA27 alone could markedly down-regulate acrB mRNA expression (Figure 6A), suggesting increased daunorubicin accumulation was related to the inhibition of $a c r B$ mRNA expression.

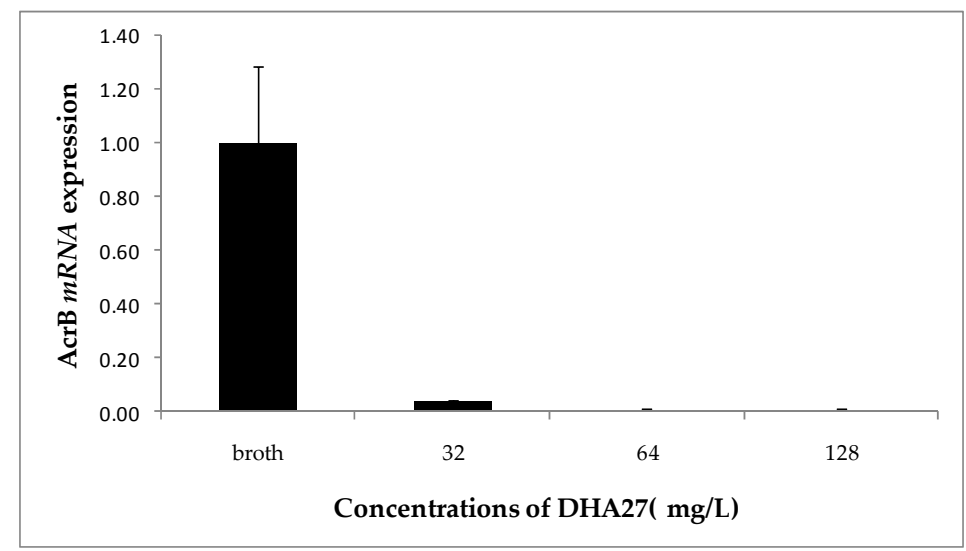

(A)

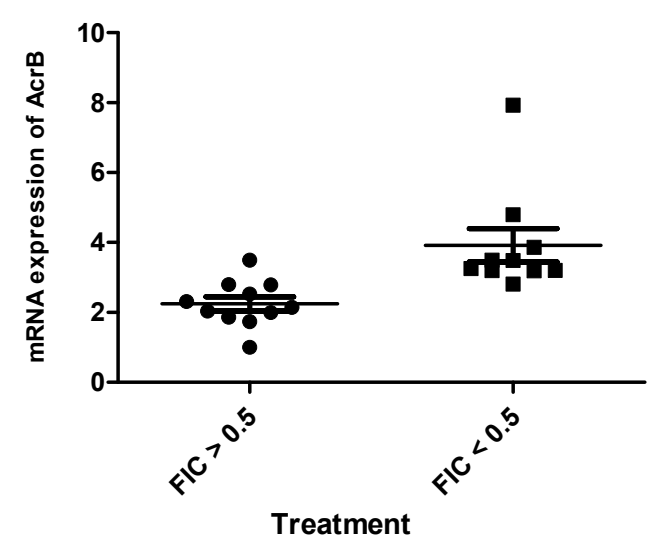

(B)

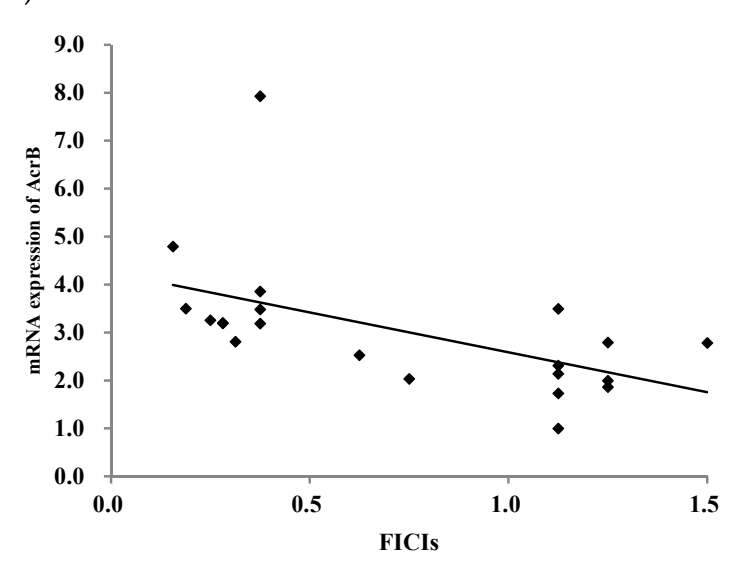

(C)

Figure 6. The effect of DHA27 on acrB mRNA expression. (A) The effect of DHA27 alone on the expression of acrB mRNA expression. E. coli clinical strains were treated with different concentration of DHA27 and inoculated into $50 \mathrm{~mL}$ of LB broth. Bacteria were cultivated at $37^{\circ} \mathrm{C}$ in a heated and shaking environmental chamber of $6 \mathrm{~h}$ and then harvested by centrifugation at $1500 \mathrm{rpm}$ for $5 \mathrm{~min}$; (B) The AcrB mRNA expression of bacteria with FICIs $>0.5$ was markedly lower than that of bacteria with FICIs < 0.5; (C) AcrB mRNA expression has negative correlation with antibacterial enhancement activities of DHA27 against them. E. coli clinical strains were inoculated into $50 \mathrm{~mL}$ of LB broth. Bacteria were cultivated at $37^{\circ} \mathrm{C}$ in a heated and shaking environmental chamber to an $\mathrm{OD}_{600}$ of 0.5 and then harvested by centrifugation at $1500 \mathrm{rpm}$ for $5 \mathrm{~min}$. RNA extraction and reverse transcription real-time PCR were performed. The real-time PCR products were detected using a MyiQ Color Fluorescence Real-Time Quantitative PCR kit (Bio-Rad). The gene fold changes were finally calculated according to the $2^{-\Delta \Delta C t}$ method for each transcript and expressed relative to the values from control group samples. 
To further investigate the correlation of DHA27's activity and acrB mRNA expression, the effect of DHA27 on acrB mRNA expression was investigated. Ten strains with FICIs lower than 0.5 (DHA27 effective) and another 10 strains with FICIs higher than 0.5 (DHA27 no effective) were chosen, and the $a c r B$ mRNA expression of these strains was tested. The results showed that $a c r B$ mRNA expression of these strains with lower FICIs (FICI $<0.5$ ) was higher than that of strains with higher FICIs (FICI > 0.5) (Figure 6B), suggesting that DHA27 had stronger antibacterial enhancement activities against strains with higher acr $B$ mRNA expression. Therefore, the aforementioned results further indicated that the degree of $a c r B$ mRNA expression was related to the bioactivity of DHA27. The correlation coefficient was $-0.538(p=0.012$, Figure $6 C)$.

\subsection{DHA27 Can Bind to Polypeptides from AcrB Obtained by Molecular Docking}

Biological experiments demonstrated DHA27 had good antibacterial enhancement activity, which was tightly related to AcrB. Herein, molecular docking was performed to further identify the possible binding sites of DHA27 to AcrB.

The results showed Gln176, Ser46 and Ser134 were probably involved inthe binding sites of AcrB to DHA27. One of the oxygen atoms of peroxide bridge on the nucleus structure interacted with Gln176. The oxygen atom of the side chain interacted with Ser46 at a distance of $2.1 \AA$. When PDB ID 2DRD were used, the sulfur atom of the side chain interacted with Ser134 at a distance of $3.1 \AA$. These interactions were all via the hydrogen binding effect (Figure 7A,B).When PDB ID 28JS and PDB ID 4DX5 were used, similar results were obtained, too (Figure S7). And DHA27 were also surrounded by Phe178, Phe610, Phe615, Phe628 which were in hydrophobic trap (Figure 7B), but there were no formation of chemical bond between DHA27 and these residues. Maybe there was no conjugated structure like benzene ring or carbonyl in DHA27 unlike AS and DHA7; it couldn't interact with hydrophobic trap through $\pi-\pi$ interactions.

To verify the binding sites of DHA27 to AcrB, four polypeptides from AcrB (named as P1, P2, $\mathrm{P} 1 \mathrm{a}$ and P2a) were synthesized. P1 and P2 were peptides from the active sites Phe134 and Ser46, respectively. P1a and P2a were respective mutated peptides at Ser134 and Ser46. P3 was an irrelevant peptide from cells. DHA27 was pre-incubated with P1, P2, P1a, P2a and P3, respectively for 30 min, and then pre-incubated DHA27 was added into E. coli ATCC 35218. Theoretically, if DHA27 bound the peptides from AcrB, pre-incubated DHA27 would lose its ability to increase the daunorubicin accumulation within ATCC 35218.

The result demonstrated that DHA27 could increase the daunorubicin accumulation within ATCC 35218 as previously mentioned ( $p<0.01$ vs. broth), and P1, P2, and P3 alone couldn't influence daunorubicin accumulation. DHA27 incubated with P3 didn't decrease daunorubicin accumulation, demonstrating that DHA27 couldn't bind to the irrelevant peptide in vitro. However, DHA27 pre-incubated with P1 and P2 lost the activity to increase daunorubicin accumulation, while it pre-incubated with P1a and P2a which were mutant peptides of P1 and P2 regained its activity to increase daunorubicin accumulation, suggesting that DHA27 could bind to P1 and P2 while it could not bind to their mutant peptides, demonstrating Ser134 and Ser46 might be involved in the binding sites of DHA27 (Figure 7C).

\subsection{DHA27 Has No Cytotoxicity in Cell Proliferation}

To investigate the cytotoxicity of DHA27 against mammalian cells, an in vitro cytotoxicity assay was performed using the mouse peritoneal macrophage RAW264.7 cell line. The result showed that 8-64 mg/L of DHA27 could not inhibit the viability of cells up to $24 \mathrm{~h}$, suggesting that DHA27 at concentrations with antibacterial enhancement activity had no cytotoxicity against RAW264.7 cells (Figure 8). 


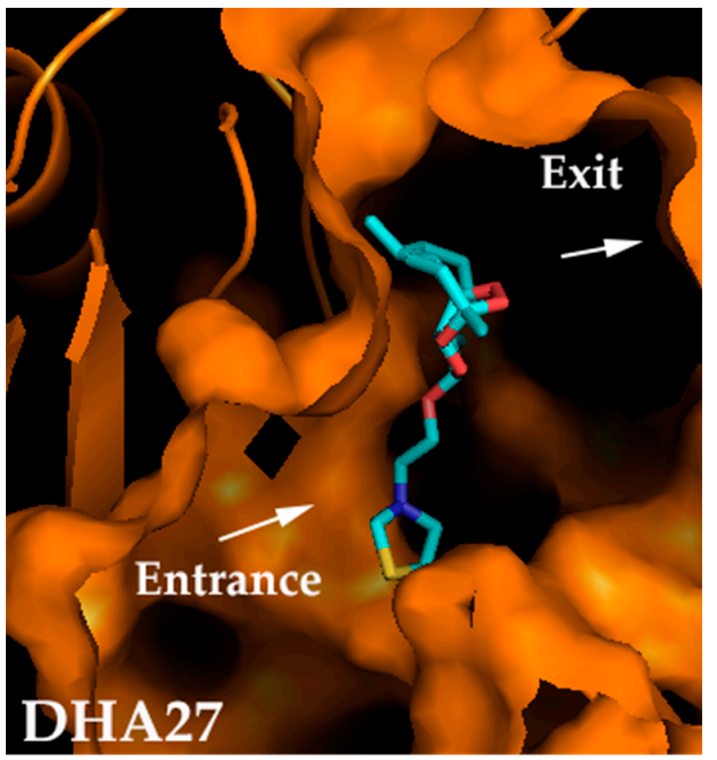

(A)

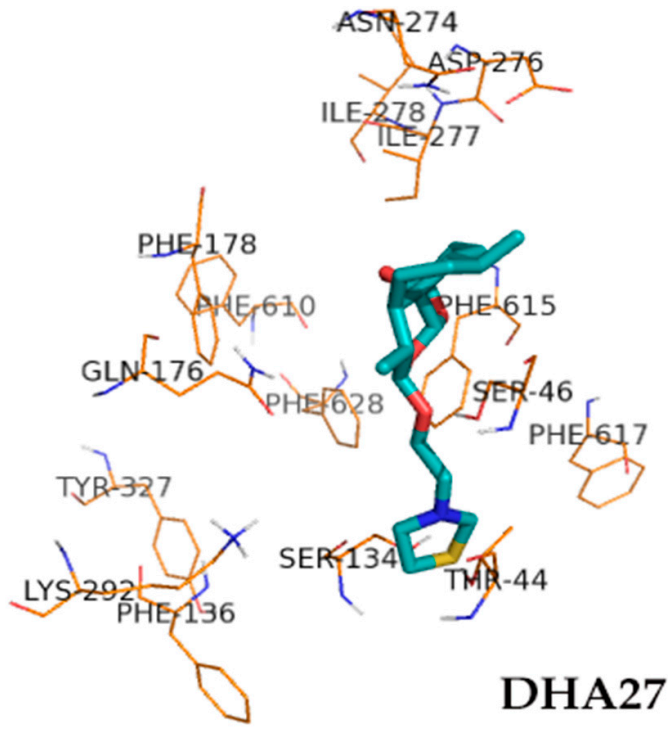

(B)

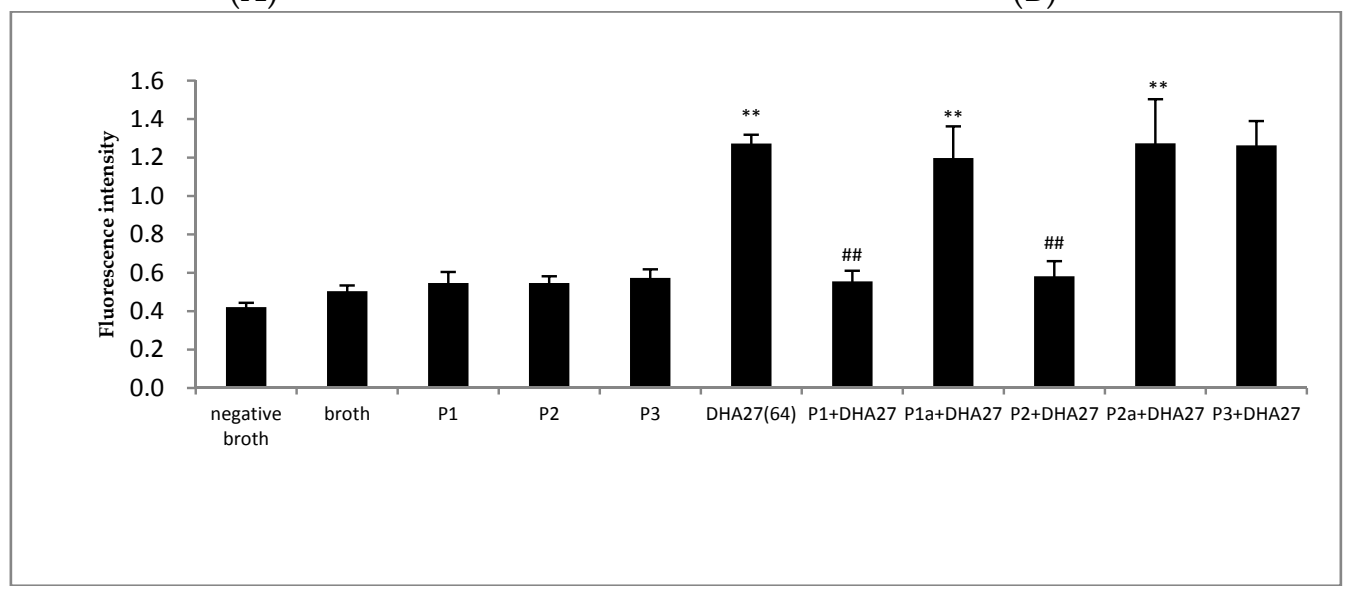

(C)

Figure 7. Molecule docking of DHA27 binding to AcrB. The crystal structure of AcrB (PDB ID, 2DRD) was obtained from Protein Data Bank. The molecular docking results were analyzed and represented in the PyMOL 1.3 visualization software. Proteins are shown in orange. The compound is shown as thick sticks colored according to the atom type (red, oxygen; cyan, carbon; white, hydrogen; dark blue, nitrogen, khaki, sulfur), and residues are shown in bluish violet and marked. (A) Longitudinal section of substrate translocation pathway when DHA27 was docked with AcrB when PDB ID 2DRD was used; (B) Cartoon view of DHA27 docked with AcrB when PDB ID 2DRD was used; (C) Effect of DHA27 on binding polypeptides from AcrB and its mutant peptides. Daunorubicin accumulation within E. coli ATCC 35218 pretreated with DHA27 and polypeptides; $64 \mathrm{mg} / \mathrm{L}$ of DHA27 and polypeptide (molar ratio: 1:1) were cultured for $30 \mathrm{~min}$ at $37^{\circ} \mathrm{C}$. This mixture was added to the $E$. coli concentrations of $1.0 \times 10^{6} \mathrm{cfu} / \mathrm{mL}$ and cultured for $6 \mathrm{~h}$ at $37^{\circ} \mathrm{C}$ in a heated and shaking environmental chamber. The bacterial pellet was resuspended, and the bacterial suspension was adjusted to an $\mathrm{OD}_{600}$ of 1.0. After co-culture with daunorubicin $(40 \mathrm{mg} / \mathrm{L})$ in the dark at $37^{\circ} \mathrm{C}$ for $30 \mathrm{~min}$, the bacteria were centrifuged at $3000 \mathrm{rpm}$ for $5 \mathrm{~min}$ to harvest the bacterial pellet. After washing with PBS $(0.2 \mathrm{mM}$, $\mathrm{pH}$ 7.2) five times, fluorospectrophotometry was used to observe daunorubicin accumulation within E. coli. The emission wavelength was $467 \mathrm{~nm}$, and the excitation wavelength was $588 \mathrm{~nm}$. ${ }^{* *} p<0.01$ compared with broth; ${ }^{\#} p<0.01$ compared with DHA27. 


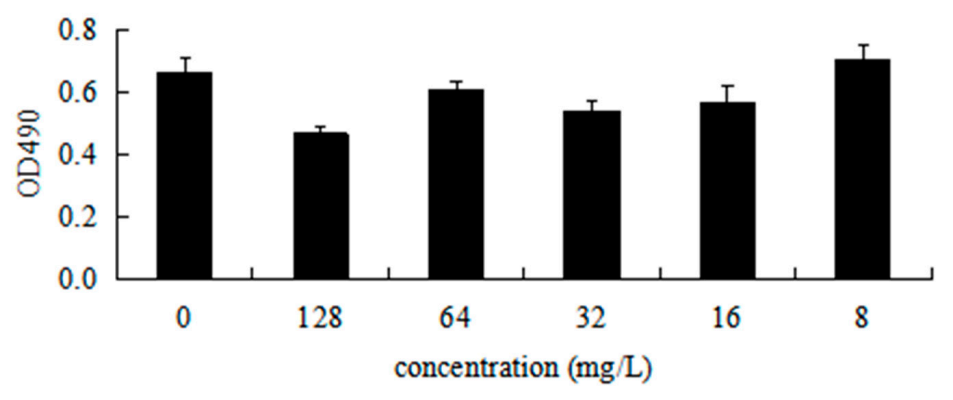

Figure 8. Effect of DHA27 at different concentrations on the growth of mouse macrophages RAW264.7. RAW264.7 cells of logarithmic phase were adjusted to the concentration of $8 \times 10^{4}$ cells per milliliter with the DMEM (10\% FBS) culture. The cells were placed on a 96 -well plate $(180 \mu \mathrm{L} /$ well $)$ and cultivated at $37{ }^{\circ} \mathrm{C}, 5 \% \mathrm{CO}_{2}$ incubator for $24 \mathrm{~h}$. DHA27 $(20 \mu \mathrm{L} /$ well $)$ was added to achieve the final concentrations of $128,64,32,16$, and $8 \mathrm{mg} / \mathrm{L}$. The blank culture was set up for control and then the template was put at $37^{\circ} \mathrm{C}, 5 \% \mathrm{CO}_{2}$ incubator for $24 \mathrm{~h}$. Mixed $100 \mu \mathrm{L}$ of low-glucose DMEM and $20 \mu \mathrm{L}$ of MTS solution were added per well. The plate was placed in an incubator at $37^{\circ} \mathrm{C}$ for $1 \mathrm{~h}$ at $5 \% \mathrm{CO}_{2}$. The absorbance was measured at $490 \mathrm{~nm}$.

\section{Discussion}

This study was the first to demonstrate that a new derivative from AS, named as DHA27, had good antibacterial enhancement activity against $E$. coli with low cytotoxicity; it was obtained based on the 3D-SAR and molecular docking experiments. It exerted its antibacterial enhancement activity via binding to the DP of AcrB and then inhibiting the function of AcrB.

AcrB plays a key role in the AcrAB-TolC efflux system, inhibition of AcrB can affect the function of AcrAB-TolC, leading to the reverse of bacterial resistance. Till now, the main known AcrB inhibitors are PA $\beta N$, NMP, D13-9001, and MBX2319 reported by others, and AS and DHA7 reported by the present study [8-10]. However, these inhibitors such as PA $\beta N$ had much more serious toxicity or lower activities; so new antibacterial enhancers should be developed.

3D-SAR studies have been found to be of great importance to designing and developing potent drugs. CoMFA used for the 3D-SAR methodology is based on the assumption that the changes in antibacterial enhancement activities are related to their 3D shape and changes in molecular properties represented by electrostatic and steric characteristics [13]. The crystal structure of AcrB is clear $[11,12,14]$, it is possible to develop new antibacterial enhancers based on the structure of AcrB. In this study, 86 new compounds having potential antibacterial enhancement activity were designed using 3D-SAR studies. To narrow down the potential active compounds, molecular docking, which could figure out the probable binding pocket of known active compounds, was used. At last, four compounds named as DHA 25-DHA 28 with a higher total score and simple synthetic routes from 22 compounds were selected and synthesized based on the results of 3D-SAR and molecular docking. Among them, DHA 27 had the best antibacterial enhancement activity.

Our previous studies reported the antibacterial enhancement activity of AS and its derivative DHA7 for the first time $[9,10]$. Although DHA7 had better activity than AS, it was still only effective against standard E. coli strains rather than clinical strains and had poor aqueous solubility as AS. Hence, they could not be developed for clinical application. Herein, DHA27 was selected from 86 compounds. Our results demonstrated it could increase the accumulation of daunorubicin and nile red within ATCC 35218 and it didn't increase nitrocefin hydrolysis, demonstrating it played its antibacterial enhancement role via increasing drug accumulation but not changing the bacterial membrane permeability.

It is well known that increased drug accumulation was related to decreased efflux and increased membrane permeability. Nitrocefin is a chromogenic $\beta$-lactam which could be hydrolyzed by the $\beta$-lactamase and then released a colored compound that can be measured at $490 \mathrm{~nm}$. The rate of nitrocefin hydrolysis is limited by the rate of diffusion across the inner membrane, hence an increased rate of hydrolysis of nitrocefin would be indicative of inner membrane permeabilization. 
E. coli AG100A lacking AcrA and AcrB and AG100A/pET28a-AcrB re-expressing AcrB, the recombinant AG100A harboring pET28a-AcrB, were used. The results showed that both DHA27 and PA $\beta N$ lost the enhancement of AMP against E. coli AG100A and regained it against E. coli AG100A/pET28a-AcrB, which demonstrated that DHA27 should be an AcrB inhibitor. Moreover, DHA27 alone markedly reduces acrB's mRNA expression of E. coli ATCC 35218 in a dose-dependent manner and its antibacterial enhancement activity is related to the degree of $a c r B$ mRNA expression in E. coli clinical strains, which further indicated that DHA27 was an AcrB inhibitor.

DHA27 had the following advantages. (1) The activity exhibited by DHA27 in vitro assays was superior to that of AS and DHA7 at the same concentrations against ATCC 35218; (2) DHA27 was effective against not only E. coli standard strains but also clinical strains when it was combined with AMP, which indicated its good potential for clinical application; (3) The activity of DHA27 was much better than that of known AcrB inhibitor PA $\beta N$ when it was combined with $\beta$-lactam antibiotics. $\beta$-lactam antibiotics are extensively used worldwide because of their safety. So, DHA27 is more valuable to be developed for clinical use than PA $\beta N$; (4) DHA27 could be converted into its hydrochloride so that it had good aqueous solubility for the possibility of its clinical use; (5) DHA27 had lower toxicity than PA $\beta N$ because it derived from ART [15]. The present data demonstrated that DHA27 had no cytotoxicity at concentrations that had antibacterial enhancement activity. Therefore, above results indicated that DHA27 exhibits the following characteristics of an AcrB inhibitor, as described by Lomovskaya et al. [16]: (i) it inhibits the extrusion or accumulation of AcrAB-TolC substrates; (ii) it potentiates the antibacterial activity of diverse agents that are substrates of AcrAB-TolC; and (iii) it does not exhibit activity against mutants lacking functional AcrAB-TolC pumps.

The crystal structure of AcrB is a homo-trimeric protein, and each protomer is in any of these three conformations: Access (loose or A), Binding (tight or B), and Extrusion (open or C) [11,12]. The substrates are transported through dual multidrug-binding pockets via the peristaltic motion of the substrate translocation pathway [3]. Different substrates bind to different sites of the binding pocket of AcrB. A number of studies [17-19] demonstrated that the majority of substrates of AcrB bound to the DP located in the periplasmic domain of the binding conformer [11], suggesting that DP played a major role in the binding and selection of substrates by AcrB [20-22]. Some antibiotics have been found to bind to the proximal binding pocket also called the access pocket (AP) in the access protomer [23,24]. AP and DP are separated by a loop rich in glycine called as G-loop.

Several AcrB inhibitors (PA $\beta N$, NMP, D13-9001, and MBX2319) and some of its substrates (MIN and DOX) have been found by molecular docking experiments. It has been demonstrated that (1) the binding positions of all inhibitors are partially overlapped [25]. The important binding sites are Phe136, Gln176, Tyr327, Phe178, Phe615, and Phe628, which are also partial sites of binding of AS, DHA7, and DHA27 to AcrB; (2) All inhibitors have higher affinities for the DP of protomer B compared with the substrate MIN. Thus, competitive binding of the inhibitors might alter the properties of substrate-binding sites, reducing the affinity of substrates to the DP of AcrB.

The most likely mechanism of inhibition of DHA27 was through competitive inhibition and/or blockage of access to the substrate-binding site of AcrB. This was in contrast to PA $\beta N$, which also increases the permeability of the inner membrane [16]. The binding positions of AS, DHA7, and DHA27 were partially overlapped and a little bit deeper (close to the gate) than those of reported other inhibitors (PA $\beta N$, NMP, D13-9001, and MBX2319) [26]. These ART derivatives are apt to interact with polar residues, while other reported inhibitors have a predilection for hydrophobic residues. The reason of this can be the difference in their structure. The structures of ART derivatives have no or only one aromatic nucleus that interacts with polar residues via hydrogen bonding, while the structures of reported inhibitors include more than one aromatic nuclei that can interact with hydrophobic residues via the ring-stacking effect.

The binding sites of DHA27 were partially overlapped with those of AS and DHA7, and previously reported AcrB inhibitors other than MBX2319 and D13-9001 [25]. The binding sites of DHA27 were verified by the competitive inhibition experiments. However, it was not directly confirmed that DHA27 had higher affinity compared with other substrates of AcrB (MIN and DOX). It is proposed 
that important binding sites for DHA27 were Gln176, Ser46, and Ser134 to influence the morphology of the substrate extrusion channel, alter the properties of substrate-binding sites, and reduce the affinity of substrates to the DP of AcrB. This prediction was supported by the polypeptide-binding assays in vitro.

\section{Materials and Methods}

\subsection{Reactants and Solvents}

Dihydroartemisinine (DHA) was purchased from Holley Wuling Mountain Pharmaceutical Corporation, Ltd. (Chongqing, China). Other synthetic materials were purchased from Aladdin (Shanghai, China). Solvents were purchased from Chuandong Chemical Co., Ltd. (Chongqing, China) and distilled in our laboratory. Daunorubicin hydrochloride for injection was obtained from Pharmacia Italia S.P.A (Milan, Italy).

\subsection{Bacterial Strains, Antibiotics, Peptides, and Drug Preparation}

E. coli ATCC 35218 was kept in the laboratory, which was a standard strain resistant to ampicillin (AMP) with high acrB mRNA expression. E. coli clinical isolates were obtained from the Department of Clinical Laboratory, Southwestern Hospital (Chongqing, China) (sample number 1-40). E. coli AG100A lacking AcrAB was donated by Professor Hiroshi Nikaido of the University of California (CA, USA). E. coli AG100A/pET28a-AcrB re-expressing AcrB, the recombinant AG100A harboring pET28a-AcrB, was constructed in the laboratory. The information on antibiotics and drugs used in this study is listed in Table S1.

The peptides named as P1 and P2 were obtained from the crystal structure of AcrB (PDB ID, 2DRD). The amino acid sequence of P1 was VSVEKSSSSFLF (number: 126-136), and that of P2 was PVAQYPTIAPPAVTIS (number: 30-46). The peptide of P3 was obtained from other proteins; the amino acid sequence was EECRGRALRLCL. P1a and P2a were mutant peptides mutated at Ser134 and Ser46. The amino acid sequence of P1a was KSSSLTFMVVG (number: 131-140), and that of P2a was PAVTILAAYPG (number: 41-50). All peptides were synthesized by SBS Genetech Co., Ltd. (Beijing, China).

\subsection{Three-Dimensional Structure-Activity Relationship with Comparative Molecular Field Analysis}

Three-dimensional structure-activity relationship (3D-SAR) and the comparative molecular field analysis (COMFA) were performed using the Sybyl 2.0 molecular modeling software (Tripos International, St. Louis, MO, USA) package, as described previously. In this study, the default CoMFA setting, which included both steric and electrostatic fields, and partial least squares regression analysis were used.

DHA7 was selected as the molecular template, and 18 compounds from previous work were used for database alignment [10]. Molecular energy minimization of each compound was calculated in the compute mode and then stored in the new database. The aligned database molecules, the steric and electrostatic energy values in CoMFA, and the biological activities of these molecules were placed in a spreadsheet. Partial least square (PLS) method was applied to generate 3D-SAR models. The PLS algorithm with the leave-one-out cross-validation method was employed to choose the optimum number of components and assess the statistical significance of each model.

\subsection{Molecular Docking}

Surflex-Dock that adopted an empirical scoring function was employed for molecular docking. The crystal structure of AcrB (PDB ID, 2DRD) was obtained from Protein Data Bank (http:/ /www. rcsb.org). The molecular docking results were analyzed and represented in PyMOL 1.3 visualization software (Program by Warren Lyford DeLano and commercial release by DeLano Scientific LLC).

\subsection{Synthesis of $12 \beta$-(2-Bromoethoxy) Dihydroartemisinin (Compound 1)}

2-bromoethyl alcohol (1.55 g, $12 \mathrm{mmol})$ and $50 \mathrm{~mL}$ of $\mathrm{Et}_{2} \mathrm{O}$ were added into a 100-mL round-bottomed flask, and then $2 \mathrm{~mL}$ of boron trifluoride etherate with ice bath cooling was added. 
DHA ( $2.85 \mathrm{~g}, 10 \mathrm{mmol})$ was finally added after stirring. The mixture was allowed to react for $5 \mathrm{~h}$ and continuously ice bath cooled and stirred. The reaction process was monitored with thin-layer chromatography (TLC). Saturated $\mathrm{NaHCO}_{3}$ was added to terminate the reaction. The aqueous layer was extracted with ethyl acetate $(\mathrm{EtOAc})(20 \mathrm{~mL} \times 2)$ after liquid separation, and then the organic layer was merged. The organic layer was washed with $20 \mathrm{~mL}$ of saturated saline solution, and then dried with anhydrous $\mathrm{Na}_{2} \mathrm{SO}_{4}$, and the solvent was removed through rotary steaming under a reduced pressure. The raw product was recrystallized with a mixed solvent of petroleum ether and EtOAc, and a 3.122-g white crystal was obtained after filtration and vacuum desiccation. The yield was 79.52\% (Figure S1).

\subsection{Synthesis of DHA25-DHA28}

Compound 1 ( $0.391 \mathrm{~g}, 1 \mathrm{mmol}), \mathrm{K}_{2} \mathrm{CO}_{3}(0.276 \mathrm{~g}, 2 \mathrm{mmol})$, and $\mathrm{YH}(1.2 \mathrm{mmol}$, Figure S2) were added to a solution of $\mathrm{CH}_{3} \mathrm{CN}(30 \mathrm{~mL})$. The mixture was allowed to react at a controlled temperature; the reaction process was monitored by TLC. Then, $15 \mathrm{~mL}$ of $\mathrm{CH}_{2} \mathrm{Cl}_{2}$ and $20 \mathrm{~mL}$ of saturated $\mathrm{NaCl}$ solution were added. The aqueous layer with $\mathrm{CH}_{2} \mathrm{Cl}_{2}(10 \mathrm{~mL} \times 2)$ was extracted after liquid separation, and then the organic layers were merged. The organic layer was washed with $20 \mathrm{~mL}$ of saturated saline solution and then dried with anhydrous $\mathrm{Na}_{2} \mathrm{SO}_{4} ; \mathrm{CH}_{2} \mathrm{Cl}_{2}$ was removed through rotary steaming under a reduced pressure. A pure product was obtained after column chromatography. The yields of DHA25-DHA 28 are shown in Figure S1. The ${ }^{1} \mathrm{H}-\mathrm{NMR}$ and ${ }^{13} \mathrm{C}-\mathrm{NMR}$ of DHA25-DHA 28 are shown in Figure S2A.

\subsection{Synthesis of DHA27 Hydrochloride}

DHA27 was dissolved in methanol $(50 \mathrm{~mL})$ and converted into the $\mathrm{HCl}$ salt by treatment with ethereal $\mathrm{HCl}$. The solvent was evaporated in vacuo. The residue was recrystallized from a mixture of $\mathrm{MeOH}$-hexanes. The ${ }^{1} \mathrm{H}-\mathrm{NMR}$ of DHA27 hydrochloride is shown in Figure S2B.

\subsection{Drug Susceptibility Assay}

A single colony from Luria-Bertani (LB) agar plates was transferred to sterile liquid LB broth (10 g/L tryptone, $10 \mathrm{~g} / \mathrm{L} \mathrm{NaCl}$, and $5 \mathrm{~g} / \mathrm{L}$ yeast extract) and cultivated aerobically in a heated and shaking 50-mL environmental chamber at $37^{\circ} \mathrm{C}$ for $12 \mathrm{~h}$. These cultures were then transferred to $500 \mathrm{~mL}$ of fresh LB broth for another $12 \mathrm{~h}$. When bacteria were in the exponential phase of growth, they were resuspended and diluted in fresh LB broth to achieve cell growth $\left(1 \times 10^{6} \mathrm{cfu} / \mathrm{mL}\right)$ that was subsequently inoculated into 96-well plates. Minimum inhibitory concentrations (MICs) were determined by serial twofold dilutions in LB broth containing different drugs in accordance with the Clinical and Laboratory Standards Institute (CLSI) 2013.

Meanwhile, the MICs of combined drugs were also observed and the fractional inhibitory concentration index (FICI) was calculated according to the method reported previously [26]. FICI $<0.5=$ synergy; $0.5-4.0=$ irrelevant $>4.0=$ antagonism .

\subsection{Dynamic Bacterial Growth}

Bacteria in the exponential phase of growth were diluted in LB broth to reach a concentration of $1.0 \times 10^{6} \mathrm{cfu} / \mathrm{mL}$. According to the MIC results, the same concentrations of AS, DHA7, and DHA27 alone, and in combination with AMP were added to bacterial suspensions. Broth and $5 \%$ dimethyl sulfoxide (DMSO) were used without drugs or antibiotic. The bacterial growth was determined by measuring $\mathrm{OD}_{600}$ at regular intervals.

\subsection{Daunorubicin Accumulation within E. coli ATCC 35218}

E. coli was inoculated into $10 \mathrm{~mL}$ of LB broth containing different concentrations of DHA27 and AS. They were cultured for $6 \mathrm{~h}$ at $37^{\circ} \mathrm{C}$ in a heated and shaking environmental chamber. The bacterial pellet was resuspended, and the bacterial suspension was adjusted to an $\mathrm{OD}_{600}$ of 1.0. All the groups were co-cultured with daunorubicin $(40 \mathrm{mg} / \mathrm{L})$ in the dark at $37^{\circ} \mathrm{C}$ for $0,10,20$, and $30 \mathrm{~min}$. 
The bacteria were centrifuged at $3000 \mathrm{rpm}$ for $5 \mathrm{~min}$ to harvest the bacterial pellet. After washing with phosphate-buffered saline (PBS) $(0.2 \mathrm{mM}, \mathrm{pH} 7.2)$ five times, fluorospectrophotometry was used to observe daunorubicin accumulation within E. coli. The emission wavelength was $467 \mathrm{~nm}$, and the excitation wavelength was $588 \mathrm{~nm}$.

\subsection{Nile Red Uptake Assay}

E. coli 35218 cells were inoculated into $10 \mathrm{~mL}$ of LB broth and cultured for $6 \mathrm{~h}$ at $37^{\circ} \mathrm{C}$ in a heated and shaking environmental chamber. Cells were harvested, and washed in phosphate-buffered saline (PBS) $(0.2 \mathrm{mM}, \mathrm{pH} 7.2) 2$ times and resuspended in the same buffer to $\mathrm{OD}_{600}$ of 1 . CCCP $(10 \mu \mathrm{mol} / \mathrm{L})$ was added to the cells. After culturing for $20 \mathrm{~min}$ at $37^{\circ} \mathrm{C}$, DHA27 $(128 \mathrm{mg} / \mathrm{L})$ and PA $\beta N(256 \mathrm{mg} / \mathrm{L})$ were added and cultured for another $20 \mathrm{~min}$ at $37^{\circ} \mathrm{C}$. Nile red was finally added to a final concentration of $5 \mu \mathrm{mol} / \mathrm{L}$ and cultured for $30 \mathrm{~min}$ at $37^{\circ} \mathrm{C}$. The bacteria cells were centrifuged at $3000 \mathrm{rpm}$ for $5 \mathrm{~min}$ to harvest the bacterial pellet and resuspended in the PBS, $0.2 \mathrm{~mL}$ of this cell suspension was transferred to a plate reader and fluorospectrophotometry was used to observe. The excitation was at $550 \mathrm{~nm}$, emission was at $640 \mathrm{~nm}$. The fluorescence of the cell suspension was followed for $100 \mathrm{~s}$, after which the efflux of nile red was triggered by rapid energization with $50 \mathrm{mmol} / \mathrm{L}$ glucose. Fluorescence was monitored for another $200 \mathrm{~s}$.

\subsection{Nitrocefin Uptake Assay}

E. coli ATCC 35218 with constitutive expression of chromosomal $\beta$-lactamase were grown in LB broth, harvested, and washed in $50 \mathrm{mmol} / \mathrm{L}$ potassium phosphate buffer. The cells were subsequently resuspended in the same buffer to $\mathrm{OD}_{600}$ of 0.5 . The cell suspension was treated with CCCP $(10 \mu \mathrm{mol} / \mathrm{L})$. Different concentrations of DHA27 (32, 64, and $128 \mathrm{mg} / \mathrm{L})$ and PA $\beta \mathrm{N}(256 \mathrm{mg} / \mathrm{L})$ were added, respectively. Nitrocefin was then added to give a final concentration of $32 \mathrm{mg} / \mathrm{L}$. Hydrolysis of nitrocefin was monitored by measuring the increase in absorbance at $490 \mathrm{~nm}$ with a plate reader.

\subsection{Competitive Inhibition Assay of DHA27 and Polypeptides from AcrB}

DHA27 (64 mg/L) and polypeptide (molar ratio, 1:1) were cultured for $30 \mathrm{~min}$ at $37{ }^{\circ} \mathrm{C}$. This mixture was added to the E. coli concentrations of $1.0 \times 10^{6} \mathrm{cfu} / \mathrm{mL}$, and the next procedure was the same as the daunorubicin accumulation assay.

\subsection{AcrB mRNA Expression Assay}

E. coli clinical strains were inoculated into $50 \mathrm{~mL}$ of LB broth. Bacteria were cultivated at $37^{\circ} \mathrm{C}$ in a heated and shaking environmental chamber to an $\mathrm{OD}_{600}$ of 0.5 and then harvested by centrifugation at $1500 \mathrm{rpm}$ for $5 \mathrm{~min}$. RNA extraction and reverse transcription were performed as described previously. The primers were added to the polymerase chain reaction (PCR) tubes and subjected to the real-time PCR. The real-time PCR products were detected using a MyiQ Color Fluorescence real-time Quantitative PCR kit (Bio-Rad, Hercules, CA, USA). The gene fold changes were finally calculated according to the $2^{-\Delta \Delta C t}$ method for each transcript and expressed relative to the values from control group samples.

\subsection{MTS Assay}

RAW264.7 cells of logarithmic phase were adjusted to the concentration of $8 \times 10^{4}$ cells per milliliter with the Dulbecco's modified Eagle's medium (DMEM) $(10 \%$ fetal bovine serum) culture. The cells were placed on a 96-well plate $(180 \mu \mathrm{L} /$ well $)$ and cultivated in a $37^{\circ} \mathrm{C}, 5 \% \mathrm{CO}_{2}$ incubator for $24 \mathrm{~h}$. DHA27 (20 $\mu \mathrm{L} /$ well) was added to achieve the final concentrations of $128,64,32,16$, and $8 \mathrm{mg} / \mathrm{L}$. The blank culture was set up for control, and then the template was put in the $37^{\circ} \mathrm{C}, 5 \% \mathrm{CO}_{2}$ incubator for $24 \mathrm{~h}$. A mixture of $100 \mu \mathrm{L}$ of low-glucose DMEM and $20 \mu \mathrm{L}$ of MTS solution was added per well. The plate was placed in an incubator at $37^{\circ} \mathrm{C}$ for $1 \mathrm{~h}$ at $5 \% \mathrm{CO}_{2}$. The absorbance was measured at $490 \mathrm{~nm}$. All data were presented as mean \pm standard deviation $(n=5)$. 


\subsection{Statistics and Presentation of Data}

Each experiment was repeated at least three times. Each datum point represented the mean of samples, and error bar denoted standard deviations. The Dunnett's multiple comparison test was used to examine the differences in the dynamic growth of E. coli ATCC 35218 and daunorubicin accumulation within E. coli ATCC 35218.

SPSS 16.0 (SPSS, Armonk, New York, NY, USA) was used for data analysis. Pearson correlation test was used to examine the relationship of $a c r B$ mRNA expression in E. coli clinical strains and the antibacterial enhancement activities of DHA27 against E. coli. A $p$ value of 0.05 was considered significant, and a $p$ value of 0.01 was considered highly significant.

\section{Conclusions}

In conclusion, DHA27 showed better antibacterial enhancement activity compared with previously reported AcrB inhibitors, and its molecular mechanism might be related to its binding to AcrB in binding conformation. Gln176, Ser46, and Ser134 were probably involved in the binding sites of AcrB. Its favorable physical and pharmacological properties and lack of cytotoxicity at effective concentrations make it a potential efflux pump inhibitor worthy of further investigation.

Supplementary Materials: Supplementary materials can be found at www.mdpi.com/1422-0067/17/11/1934/s1.

Acknowledgments: This work was supported by a grant from the basic and frontier research projects of Chongqing, China, cstc2015jcyjA10097, and grant from National Natural Science Foundation of China (No. 81173103).

Author Contributions: Hong Zhou has full access to all of the experimental design and data in the study. Yi Song performed the experiments. Rongxin Qin aided the performance of the experiments and wrote the manuscript. Xichun Pan, Qin Ouyang, Tianyu Liu, Yingchun Chen and Bin Li participated in the experiments and offered the reference opinions, Zhaoxia Zhai performed some part of the experiments. Their contributions are reflected by their order in the author list.

Conflicts of Interest: The authors declare no conflict of interest.

\section{References}

1. Nikaido, H.; Takatsuka, Y. Mechanisms of RND multidrug efflux pumps. Biochim. Biophys. Acta 2009, 1794, 769-781. [CrossRef] [PubMed]

2. Ruggerone, P.; Murakami, S.; Pos, K.M.; Vargiu, A.V. RND efflux pumps: Structural information translated into function and inhibition mechanisms. Curr. Top. Med. Chem. 2013, 13, 3079-3100. [CrossRef] [PubMed]

3. Yamaguchi, A.; Nakashima, R.; Sakurai, K. Structural basis of RND-type multidrug exporters. Front. Microbial. 2015, 6, 327. [CrossRef] [PubMed]

4. Ma, D.; Cook, D.N.; Alberti, M.; Pon, N.G.; Nikaido, H.; Hearst, J.E. Molecular cloning and characterization of acrA and acrE genes of Escherichia coli. J. Bacteriol. 1993, 175, 6299-6313. [CrossRef] [PubMed]

5. Mahamoud, A.; Chevalier, J.; Alibert-Franco, S.; Kern, W.V.; Pagès, J.M. Antibiotic efflux pumps in Gram-negative bacteria: The inhibitor response strategy. J. Antimicrob. Chemother. 2007, 59, 1223-1229. [CrossRef] [PubMed]

6. Tegos, G.P.; Haynes, M.; Strouse, J.J.; Mohiuddin, M.K.; Bologa, C.G.; Oprea, T.I.; Sklar, L.A. Microbial efflux pump inhibition: Tacticsand strategies. Curr. Pharm. Des. 2011, 17, 1291-1302. [CrossRef] [PubMed]

7. Bush, K.; Courvalin, P.; Dantas, G.; Davies, J.; Eisenstein, B.; Huovinen, P.; Jacoby, G.A.; Kishony, R.; Kreiswirth, B.N.; Kutter, E.; et al. Tackling antibiotic resistance. Nature reviews. Microbiology 2011, 9, 894-896. [PubMed]

8. Opperman, T.J.; Nguyen, S.T. Recent advances toward a molecular mechanism of efflux pump inhibition. Front. Microbiol. 2015, 6, 421. [CrossRef] [PubMed]

9. Li, B.; Yao, Q.; Pan, X.C.; Wang, N.; Zhang, R.; Li, J.; Ding, G.; Liu, X.; Wu, C.; Ran, D.; et al. Artesunate enhances the antibacterial effect of $\beta$-lactam antibiotics against Escherichia coli by increasing antibiotic accumulation via inhibition of the multidrug efflux pump system AcrAB-TolC. J. Antimicrob. Chemother. 2011, 66, 769-777. [CrossRef] [PubMed] 
10. Wu, C.; Liu, J.; Pan, X.C.; Xian, W.Y.; Li, B.; Peng, W.; Wang, J.F.; Yang, D.C.; Zhou, H. Design, synthesis and evaluation of the antibacterial enhancement activities of amino dihydroartemisin in derivatives. Molecules 2013, 18, 6866-6882. [CrossRef] [PubMed]

11. Murakami, S.; Nakashima, R.; Yamashita, E.; Matsumoto, T.; Yamaguchi, A. Crystal structures of a multidrug transporter reveal a functionally rotating mechanism. Nature 2006, 443, 173-179. [CrossRef] [PubMed]

12. Seeger, M.A.; Schiefner, A.; Eicher, T.; Verrey, F.; Diederichs, K.; Pos, K.M. Structural asymmetry of AcrB trimer suggests a peristaltic pump mechanism. Science 2006, 313, 1295-1298. [CrossRef] [PubMed]

13. Singh, S.; Supuran, C.T. 3D-QSAR CoMFA studies on sulfonamide inhibitors of the Rv3588c beta-carbonic anhydrase from Mycobacterium tuberculosis and design of not yet synthesized new molecules. J. Enzym. Inhib. Med. Chem. 2014, 29, 449-455. [CrossRef] [PubMed]

14. Nakashima, R.; Sakurai, K.; Yamasaki, S.; Hayashi, K.; Nagata, C.; Hoshino, K.; Onodera, Y.; Nishino, K.; Yamaguchi, A. Structural basis for the inhibition of bacterial multidrug exporters. Nature 2013, 500, 102-106. [CrossRef] [PubMed]

15. Lomovskaya, O.; Bostian, K.A. Practical applications and feasibility of efflux pump inhibitors in the clinic: A vision for applied use. Biochem. Pharmacol. 2006, 71, 910-918. [CrossRef] [PubMed]

16. Lomovskaya, O.; Warren, M.; Lee, A.; Galazzo, J.; Fronko, R.; Lee, M.; Blais, J.; Cho, D.; Chamberland, S.; Renau, T.; et al. Identification and characterization of inhibitors of multidrug resistance efflux pumps in Pseudomonas aeruginosa: Novel agents for combination therapy. Antimicrob. Agents Chemother. 2001, 45, 105-116. [CrossRef] [PubMed]

17. Bohnert, J.A.; Schuster, S.; Fahnrich, E.; Trittler, R.; Kern, W.V. Altered spectrum of multidrug resistance associated with a single point mutation in the Escherichia coli RND-type MDR efflux pump YhiV (MdtF). J. Antimicrob. Chemother. 2007, 59, 1216-1222. [CrossRef] [PubMed]

18. Bohnert, J.A.; Schuster, S.; Seeger, M.A.; Fähnrich, E.; Pos, K.M.; Kern, W.V. Site-directed mutagenesis reveals putative substrate binding residues in the Escherichia coli RND efflux pump AcrB. J. Bacterial 2008, 190, 8225-8229. [CrossRef] [PubMed]

19. Bohnert, J.A.; Karamian, B.; Nikaido, H. Optimized Nile Red efflux assay of AcrAB-TolC multidrug efflux system shows competition between substrates. Antimicrob. Agents Chemother. 2010, 54, 3770-3775. [CrossRef] [PubMed]

20. Takatsuka, Y.; Chen, C.; Nikaido, H. Mechanism of recognition of compounds of diverse structures by the multidrug efflux pump AcrB of Escherichia coli. Proc. Natl. Acad. Sci. USA 2010, 107, 6559-6565. [CrossRef] [PubMed]

21. Wehmeier, C.; Schuster, S.; Fahnrich, E.; Kern, W.V.; Bohnert, J.A. Site-directed mutagenesis reveals amino acid residues in the Escherichia coli RND efflux pump AcrB that confer macrolide resistance. Antimicrob. Agents Chemother. 2009, 53, 329-330. [CrossRef] [PubMed]

22. Vargiu, A.V.; Nikaido, H. Multidrug binding properties of the AcrB efflux pump characterized by molecular dynamics simulations. Proc. Natl. Acad. Sci. USA 2012, 109, 20637-20642. [CrossRef] [PubMed]

23. Nakashima, R.; Sakurai, K.; Yamasaki, S.; Nishino, K.; Yamaguchi, A. Structures of the multidrug exporter AcrB reveal a proximal multisite drug-binding pocket. Nature 2011, 480, 565-569. [CrossRef] [PubMed]

24. Eicher, T.; Cha, H.J.; Seeger, M.A.; Brandstätter, L.; El-Delik, J.; Bohnert, J.A.; Kern, W.V.; Verrey, F.; Grütter, M.G.; Diederichs, K.; et al. Transport of drugs by the multidrug transporter AcrB involves an access and a deep binding pocket that are separated by a switch-loop. Proc. Natl. Acad. Sci. USA 2012, 109, 5687-5692. [CrossRef] [PubMed]

25. Odds, F.C. Synergy, antagonism, and what the chequerboard puts between them. J. Antimicrob. Chemother. 2003, 52, 1. [CrossRef] [PubMed]

26. Vargiu, A.V.; Ruggerone, P.; Opperman, T.J.; Nguyen, S.T.; Nikaido, H. Molecular mechanism of MBX2319 inhibition of Escherichia coli AcrB multidrug efflux pump and comparison with other inhibitors. Antimicrob. Agents Chemother. 2014, 58, 6224-6234. [CrossRef] [PubMed]

(C) 2016 by the authors; licensee MDPI, Basel, Switzerland. This article is an open access article distributed under the terms and conditions of the Creative Commons Attribution (CC-BY) license (http://creativecommons.org/licenses/by/4.0/). 